\title{
Analyses of Move Structure and Verb Tense of Research Article Abstracts in Applied Linguistics Journals
}

\author{
Fan-ping Tseng \\ Department of English, National Taiwan Normal University \\ 162, HePing East Road, Section 1, Taipei, 106, Taiwan, ROC \\ Tel: 886-2-7734-1800Ｅ-mail: tsengfp@gmail.com
}

Received: April 6, $2011 \quad$ Accepted: May 6, $2011 \quad$ doi:10.5539/ijel.v1n2p27

\begin{abstract}
This study examined 90 research article abstracts in three applied linguistics journals (i.e., TESOL Quarterly, Applied Linguistics, and Language Learning) from two dimensions: the move structure features and the verb tense of each move. The results showed that the abstracts analyzed tended to take a four-move structure instead of a five-move one as proposed in literature. In addition, since some publishers have word limits on abstract length, authors would usually follow the publisher's guideline accordingly, thus there existing some differences concerning the move structure features among the abstracts in the three journals. In terms of the verb tense in each move, the preferred pattern was as follows: the present tense usually occurred in the first, second, and fifth move, while the past tense was often used in the third and fourth moves. It was also found that there were some variations between the abstracts written by native speakers and nonnative speakers of English. It is hoped that with detailed analyses of abstracts, the results of this study may serve as a complement to the guidelines for novice writers to construct a proper research article abstract in applied linguistics.
\end{abstract}

Keywords: Move structure analyses, Verb tense analyses, Research article, Abstract, Applied linguistics, Journals

\section{Introduction}

In academic prose, abstracts have become an essential and inalienable part of research articles. Almost every scholarly journal, written either in English or in other languages, would require an abstract to be submitted along with the original research article (Martín, 2003). Abstracts have become a gateway into the research literature (Hartley \& Benjamin, 1998) and are a useful tool of mastering and managing the ever increasing information flow in the scientific community (Ventola, 1994). For example, abstracts not only serve as a key to understanding fully the arguments of the original articles (Swales, 1990), but also provide readers with some language preparation for the full texts (Cross \& Oppenheim, 2006). Moreover, if presented in a structured format (note 1), abstracts are easier to read, search and recall, and often contain more information than the traditional ones (Hartley, Sydes \& Blurton, 1996; Hartley \& Sydes, 1997; Hartley \& Benjamin, 1998). Given their important roles and functions in research communities, abstracts, a specific genre in its own right (Lorés, 2004), have received considerable attention and have been examined from different perspectives in recent years.

Previous studies of research article abstracts have covered several different disciplines, such as medicine, psychology, and applied linguistics, and have mainly focused on two dimensions of abstracts (note 2): the rhetorical organization or the move structure (e.g., Cross \& Oppenheim, 2006; Lau, 2004; Santos, 1996) and the linguistic realizations of the moves (e.g., Busch-Lauer, 1995; Pho, 2008). Although quite a few studies have analyzed research article abstracts, only three studies focused on abstracts in applied linguistics (i.e., Lorés, 2004; Pho, 2008; Santos, 1996). Santos (1996) was probably the first endeavor in trying to establish the textual organization of applied linguistics abstracts. Lorés (2004) and Pho (2008) were two small-scale studies, focusing on the thematic organization and authorial stance of abstracts respectively. Due to the fact that different disciplines may have different conventions to write abstracts and in order to present a more detailed feature of abstracts in applied linguistics, the present study, aiming to extend Santos's (1996) work, examined 90 applied linguistics abstracts from two dimensions: the move structure and the verb tense of the moves. It is hoped that the results of this investigation can benefit novice writers in their construction of research article abstracts in applied linguistics.

In order to portray a clearer picture of the features of research article abstracts in applied linguistics, the present study addressed the following three questions:

1. What are the features of the move structure of abstracts in terms of abstract length, move frequency, move pattern, and words per move? 
2. What is the preferred verb tense of each move in the abstracts?

3. Are there any significant differences of the abstract features among different journals in applied linguistics?

\section{Literature Review}

An abstract, according to Bhatia (1993), is 'a description or factual summary of the much longer report, and is meant to give the reader an exact and concise knowledge of the full article' (p. 78). In other words, it is 'an abbreviated, accurate representation of the contents of a document' (ANSI, 1979: 1). Basically, a good abstract should have the following features: accurate, self-contained, concise and specific, non-evaluative, and coherent and readable (American Psychological Association, 2001).

In view of the importance of abstracts to the academic communities and their different format from full research articles, several books have included guidelines as to how abstracts should be written or structured. For example, Weissberg and Buker (1990) presented a five-move model of an abstract in their textbook. The five moves are Background, Purpose, Method, Results, and Conclusion, with the first move (Background) being optional. Similarly, Hyland (2000) proposed a five-move structure to analyze academic abstracts: Introduction, Purpose, Method, Product, and Conclusion. Swales and Feak (2004), in their handbook, likewise, suggested that structured abstracts should have five elements as a paper would, namely, Background, Aim, Method, Results, and Conclusion. From these guidelines, it can be seen that a five-move model is a suggested structure of an abstract although the moves are entitled differently in different books.

Despite the preferred abstract structure suggested in the above handbooks, the actual practice of abstracting in academic journals does not seem to conform to the model completely. For instance, Anderson and Maclean (1997) analyzed 80 medical abstracts and found that although the majority of their abstracts were in accordance with the Weissberg and Bucker's (1997) model, a considerable number differed, with one or more moves missing. Lau (2004), employing and adapting Hyland's (2000) model, examined 80 abstracts relating to life science, 50 of which were written by Taiwanese PhD students, and 30 by foreign scholars. The results showed that nearly half of the students' abstracts lacked the moves of Background (Introduction in Hyland 2000), Purpose, and Method, while most of the scholars' abstracts contained five moves, with the exception of Method. Cross and Oppenheim (2006) analyzed 12 abstracts in the field of protozoology. They found their abstracts encapsulated in five moves: Relation to other research, Purpose, Methodology, Summarizing the results, and Discussing the research. Their results indicated that only moves 3 and 4, Methodology and Summarizing the results, were obligatory moves while the other three were not. These studies seem to suggest that different disciplines may adopt different move structures in their abstracts.

Regarding abstracts in applied linguistics, Santos (1996) examined 94 abstracts and proposed a five-move pattern: (1) Situating the research, (2) Presenting the research, (3) Describing the methodology, (4) Summarizing the results, and (5) Discussing the research. Among the 94 abstracts examined, it was found that almost all abstracts contained Move 2 and Move 3, about 80\% included Move 4, about 53\% had Move 5, and only 43\% included Move 1. The results may suggest that Moves 2, 3, and 4 are obligatory moves in applied linguistics abstracts. Based on Santos's (1996) model, Pho (2008) analyzed the move structure of 30 abstracts, 20 in the field of applied linguistics, and 10 in educational technology. The results showed that all 20 applied linguistics abstracts included Moves 2, 3, and 4, 80\% of the abstracts contained Move 5, and only 45\% had Move 1 . The remaining 10 abstracts in educational technology also revealed a similar pattern, with Moves 2, 3, and 4 as obligatory moves. Pho's (2008) results were generally in line with Santos (1996). However, since Pho's (2008) study involved only 20 abstracts in applied linguistics, a study with a larger number of samples is needed if we want to have a clear, up-to-date picture of the overall move structure of abstracts in applied linguistics.

Another focus of the examination of abstracts in previous research is the linguistic realizations of the moves. Nevertheless, most of these studies appeared to analyze the lexis of the moves (e.g., Anderson \& Maclean, 1997; Lau, 2004; Santos, 1996), and little research, except for Salager-Meyer (1992), has paid attention to the verb tense of the moves in its own right. Salager-Meyer (1992) examined 84 medical abstracts in research papers, case reports, and review articles, and found that different verb tenses perform different functions. For example, the past tense is concerned with the history type of discourse, so it is widely used in the moves of Purpose, Methods, Results, and Case presentation. The present tense serves the purpose of enhancing and emphasizing the generalizability of specific findings, and is thus prevalent in the moves of Conclusion, Recommendation, and Data synthesis.

Salager-Meyer's (1992) study exemplifies how medical abstracts can be constructed in terms of verb tense. In fact, the tense usage in abstracts is quite complicated as acknowledged by Swales and Feak (2004), who mentioned that although the opening statements and conclusions are often in the present tense, there appears to be considerable disciplinary and individual tense variation with sentences dealing with results' (p. 283). Given the fact that little research has examined the usage of verb tense per se, it is deemed appropriate to investigate the verb tense of moves as a linguistic realization element in applied linguistics abstracts. 


\section{Method}

\subsection{The Corpus}

The corpus of the study consisted of 90 research article abstracts randomly selected from three journals in the field of applied linguistics: 30 from TESOL Quarterly (TQ), 30 from Applied Linguistics (AL), and 30 from Language Learning (LL). The three journals were chosen because of the following reasons. First, the three journals are among the top seven journals (note 3 ) in applied linguistics according to quality indicators (Egbert, 2007), thus considered aptly representing the core research or the status quo in the field of applied linguistics. Second, the three journals' abstracts were once analyzed in Santos (1996); therefore, the results of the present study could be compared with those of Santos (1996) to determine whether the abstracting practice has changed over time from 1990 as examined in Santos (1996) to 2007 as examined in the present study. Third, the three journals belong to three different publishers which might have different requirements in terms of abstracting (note 4). Examining abstracts from different journal publishers, thus, might reveal some within-disciplinary variation of the abstracting practice.

The procedure for the construction of the corpus was as follows. First, all the research articles with abstracts (excluding reviews, brief reports and summaries, forum articles and articles in the supplementary issues) in the three journals from the year 2005 to 2007 were compiled, resulting in 70 articles in TQ, 64 in AL, and 55 in LL. Second, with the application of stratified sampling (Brown, 1988), 30 articles were randomly selected from the three journals, with 10 articles from each year in each journal. However, given the fact that the rhetorical structure of empirical research articles may be different from that of theoretical ones, only the data-based, empirical research articles were included in the corpus.

\subsection{Analysis of Move Structure Features}

Santos's (1996) five-move pattern for abstracts in applied linguistics was adopted as the framework for move analysis of the abstracts in the present study. Since Swales and Feak's (2004) model (i.e., Background, Aim, Method, Results, and Conclusion) is similar to Santos's (1996) pattern, it was decided, for the purposes of brevity and clarity, to use the names of Swales and Feak's (2004) five elements to represent Santos's (1996) five moves. The framework for move analysis is shown in Table 1.

Following Santos (1996) and Holmes (1997), the basic unit for move analysis in this study was sentence. However, given the fact that abstracts are condensed texts, and that there has been evidence of move embedding in abstracts (e.g., Anderson \& Maclean, 1997; Lau, 2004; Pho, 2008; Santos, 1996), clause or phrase was also used as the analytical unit in some cases as shown in examples 1 and 2 (note 5):

1. Statistical calculations yielded 4 distinct motivational groups (R), and we interpret this classification within Dörnyei's L2 Motivational Self System (M). [LL 21]

2. Using a corpus-based approach (M), this paper investigates the construction of stance in finite reporting clauses with that-clause complementation (A). [AL 16]

Each of the abstracts in the corpus was coded and analyzed twice by the present researcher using the above five-move model, and the intra-coder reliability was .97. After each abstract was coded into different moves, other features, such as the opening and closing moves and the number or words in each move, were then examined. An example of the abstract feature analysis is presented in Table 2.

\subsection{Analysis of the Verb Tense of Moves}

The study focused on two verb tenses of the moves, namely, the present tense (including the present perfect) and the past tense. The purpose of the analysis was to figure out the preferred verb tense used in each move of an abstract. The analysis procedure was as follows. First, if a move was represented by a sentence, the verb tense of that sentence was the verb tense of the move (example 3). Second, if a move was realized in a clause or a phrase, then the verb tense of that move was not included in the data analysis procedure (example 4). Third, if a move was represented by several sentences which had both present tense and past tense, then both tenses were included in the data bank (example 5).

3. Reading is a complex skill that is critical to ELLs' academic achievement. (B) $\rightarrow$ present tense [TQ 2]

4. Using a mixed-method design, .... (M) $\rightarrow$ verb tense not included [TQ 3]

5. This paper gives an account of a project exploring 12- and 13-year-old children's uses of strategies while solving reading and writing test tasks in English as a foreign language (EFL). The study was conducted to provide insights into how learners go about solving tasks and what they think and rely on while doing them. (A) $\rightarrow$ present tense and past tense [LL 19]

\subsection{Analysis of Abstract Features in Three Journals}

In addition to qualitative analyses of the move structure and the verb tense, quantitative measures were employed to analyze the other features of the abstracts, namely, the length of an abstract, the number of sentences in an 
abstract, the number of words in each move, and the units of move in each abstract. Data of these features were analyzed with analysis of variance (ANOVA) on the SPSS 13.0 to examine whether there were any significant differences concerning these features among the three journals in applied linguistics.

\section{Results and Discussion}

\subsection{Features of the Move Structure of Abstracts}

The following analyses include the distribution of the five moves, the move structures, and the distribution of the opening and closing moves of abstracts.

The results of the five move distribution of abstracts are shown in Table 3, which demonstrates that three moves seemed to be obligatory in these applied linguistics abstracts. They were Aim, Method, and Results, each of which occurred in over $90 \%$ of the abstracts. On the other hand, Move 1 (Background) occurred in only $41 \%$ of the abstracts, and Move 5 (Conclusion), about 74\%. The results, in general, are in accordance with Santos (1996) (note 6), in that Move 2 and Move 3 were obligatory while Move 1 seemed optional. Yet, a minor difference exists between the present study and Santos (1996), in that the present corpus contained a higher percentage of Move 4 (91\%) and Move 5 (74\%) than Santos's (1996) corpus. The reason might be attributed to the fact that the present study included only the empirical research, the Results of which are considered an important part to report in the abstract, while Santos (1996) might include theoretical studies as well as empirical ones.

The pattern of move distribution in the present study more resembles that in Pho's (2008), in which Moves 2, 3, and 4 were obligatory and Move 5 and Move 1 occurred in $80 \%$ and in $45 \%$ of the abstracts. Taken together the results of Santos (1996), Pho (2008) and the present study, it seems clearly that applied linguistics abstracts tend to take a four-move structure instead of a five-move one, and these abstracts generally conform to Weissberg and Buker's (1990) model, in which the first move (Background) is optional. In addition, the results demonstrate that the abstracting practice has been quite stable over the past two decades since there is little variation in the distribution of the five moves.

Table 3 also indicates some different patterns of the move distribution among the three journals. For one, AL abstracts had a higher percentage of Move 1 (Background) than the other two journals. For another, TQ abstracts had a higher percentage of Move 5 (Conclusion) than the other two. Despite these two differences, almost all abstracts in the three journals included the three obligatory moves mentioned above.

An analysis of the move structure of each abstract in the corpus revealed that there were many different move structures among the abstracts (note 7). Table 4 highlights two patterns in the corpus: the five-move structure and the four-move structure, since the former is the model discussed in this study and the latter is a preferred model found in the literature and in the present study (note 8). Table 4 demonstrates that the four-move structure is more prevalent than the five-move structure in the corpus abstracts. If the two sets of data are pooled together (i.e., $22 \%+39 \%$ ) since the five moves also include the four moves, then the result would show that $61 \%$ of the abstracts contain at least four moves, which is higher than the percentage of abstracts containing five moves $(22 \%)$. This again suggests that Move 1 (Background) is an optional move and that a four-move structure is more likely to appear in applied linguistics abstracts.

Table 4 also reveals two differences among the three journals. First, TQ abstracts had a higher percentage of containing at least four moves (80\%) than AL abstracts (53\%) and LL abstracts (50\%). Second, abstracts in AL contained more five moves $(33 \%)$ than four moves $(20 \%)$, which is different from the other two journals. This result is in line with the previous finding that AL abstracts had a higher percentage of Move 1 (Background) than the other two journals. The fact that AL abstracts had more Move 1 than the other abstracts can also be found in Table 5, which presents the opening and closing moves of the abstracts in the corpus.

Although the American Psychological Association (2001) has suggested that an abstract can begin with purpose, results or even conclusion, Table 5 shows that the abstracts in the corpus tended to open with Move 2 (Aim) instead of Move 1 (Background), and that no abstracts opened with Move 4 (Results) or Move 5 (Conclusion). Among the three journals, however, AL abstracts are rather different from the others, in that they began more often with Move 1 than with Move 2. This result is explicable given the previous findings that AL abstracts had a higher percentage of Move 1 and a higher percentage of the five-move structure.

Regarding the closing moves, about $74 \%$ of the abstracts closed with Move 5 (Conclusion), about $22 \%$ with Move 4 (Results), few with Move 2 (Aim) and Move 3 (Method), and none with Move 1 (Background). Among all the abstracts, TQ abstracts had a higher percentage of Move 5 as the closing move than the other abstracts, which reflects the fact that TQ abstracts contained more Move 5s than the others as discussed earlier.

Taken together the results of the above analyses so far, the applied linguistics abstracts in the corpus generally have the following features. First, the abstracts tend to have a four-move structure instead of a five-move one. The first move, Background, is likely to be an optional move in these abstracts. Second, the abstracts usually begin with Move 2 (Aim) or Move 1 (Background), and end with Move 5 (Conclusion) or Move 4 (Results). Third, there is some variation in the abstracts among the three journals. For one, AL abstracts have a higher 
percentage of Move 1 (Aim) than the others, thus opening more often with Move 1. For another, TQ abstracts contain more Move 5 (Conclusion) than the other abstracts, thus ending more often with Move 5.

\subsection{Abstract Features among the Three Journals}

The following quantitative analyses consist of features of the abstract length, the number of sentences in an abstract, the number of move units, and the number of words in each move. The descriptive statistics of these features are shown in Table 6.

Table 6 presents a more detailed picture of the components of the applied linguistics abstracts. First, the length of the corpus abstracts was usually within 200 words, the mean length being 164 words. The mean length, though exceeding 120 words as required by LL (see note 4), is acceptable by TQ, which requires an abstract within 200 words. Second, the abstracts usually included 6 sentences, within 4 moves. Third, among the five moves, Move 4 (Results) was the longest, suggesting that the focus of these abstracts was on the results, thus being informative abstracts as required by TQ. On the other hand, Move 1 (Background) was the shortest, suggesting that it was less attended to. This confirms the previous finding that Move 1 is an optional move in applied linguistics abstracts.

The descriptive statistics of the above features among the three journal abstracts are presented in Appendix B. Data of these features were then analyzed by ANOVA and Scheffe's method of post-hoc comparison, and the results are shown in Appendix C. Some significant differences among the features of the three journal abstracts were found. They were the abstract length, the number of sentences in an abstract, the number of move units, the number of words in Move 1(Background), and the number of words in Move 5(Conclusion).

First, the mean length of LL abstracts (134.87 words) was shorter than that of TQ abstracts (171.97 words) and of AL abstracts (184.20 words), and the difference was statistically significant. This may be due to the different requirements of journal publishers: the LL publisher requires an abstract of 100 to 120 words, and the TQ publisher asks for an abstract less than 200 words. Although the LL abstracts in the corpus still exceeded the length limit required by the publisher, they were generally shorter compared with the other abstracts. Since the AL publisher sets no word limit on abstracts, the AL abstracts were thus found to be longer than the other abstracts. Second, there was a significant difference between the number of sentences of TQ abstracts (6.83) and that of LL abstracts (5.43). Moreover, the number of move units of TQ abstracts (4.73) was significantly higher than that of LL abstracts (4.00). These two findings could be explained by the fact that LL abstracts were generally shorter than TQ abstracts. Third, in terms of the number of words in each move, AL abstracts used significantly more words (34.80 words) in describing Move 1 (Background) than TQ abstracts (16.57 words) and LL abstracts ( 8.93 words) did. This result coincides with the previous finding that AL abstracts contained a higher percentage of Move 1 than the other abstracts. It now seems obvious that the reason why AL abstracts were longer than the other abstracts was that $\mathrm{AL}$ abstracts contained more words describing Move 1 . Thus, it can be inferred that when authors have more freedom to write abstracts of any length, like the AL authors, they will usually present a clear background (Move 1) of their research in the abstracts. Regarding Move 5 (Conclusion), TQ abstracts used significantly more words (32.77 words) than LL abstracts ( 15.5 words) did, which reflects the finding that TQ abstracts had more Move 5s than LL abstracts.

These within-disciplinary differences of abstract features can generally be attributable to different requirements by the publishers. The implication of the above findings is that when a publisher requires a shorter abstract, authors would tend to construct an abstract of a four-move structure, omitting Move 1 (Background), or tend to use few words to describe Move 1 and Move 5 (Conclusion). Take the LL abstracts in the corpus for example. Compared with abstracts in the other two journals, LL abstracts contained fewer Move 1s (see Table 3), used fewer words in Move 1 and Move 5 (see Appendix B). Therefore, based on the word limit set by the publisher, authors will write abstracts strategically; namely, they will use the allowed-number-of-words to focus on the Aim, Method, and Results of their studies. While there is no specifications for abstracts from the publisher, authors can be as verbose as they want, for example, describing the Background of their research more clearly, as the AL authors did.

\subsection{Verb Tense of the Abstract Moves}

The frequency of the verb tense in each move is presented in Table 7 . The data show that the present tense was a preferred tense in Move 1 (Background), Move 2 (Aim), and Move 5 (Conclusion), and that the past tense was used more frequently in Move 3 (Method), and Move 4 (Results). One thing worthy of note is that among the 32 abstracts which used the present tense in Move 1, 18 of them (56\%) actually adopted the present perfect tense.

When comparing the results of the present study with those of Salager-Meyer (1992), similarities and differences can be found. For example, in both studies, the present tense was used in Move 5 (Conclusion), and the past tense was used in Move 3 (Method) and Move 4 (Results). However, in Salager-Meyer (1992), Move 2 (Aim) was realized in the past tense, while in this study Move 2 was realized in the present tense. This difference might be due to some disciplinary variation (i.e., medicine vs. applied linguistics) concerning verb tense usage in 
writing abstracts.

Results of the cross-journal examination of verb tense in each move are shown in Appendix D. The data suggest some variation of tense usage among the three journal abstracts. A most striking difference is that about $67 \%$ of the AL abstracts used the present tense in Move 4 (Results) while less than $20 \%$ of the TQ and LL abstracts did so. This finding echoed Swales and Feak's (2004) observation that "there appears to be considerable disciplinary and individual tense variation with sentences dealing with results" (p. 283). Since the present tense is used to describe results with continuing applicability (American Psychological Association 2001), authors of the AL abstracts are more likely to generalize their results than those of the other abstracts. Another difference among the three journal abstracts is that AL abstracts had a higher percentage (42\%) of using the present tense in Move 3 (Method) than TQ abstracts (17\%) and LL abstracts (8\%). These two observations concerning AL abstracts seem to suggest that the present tense is a preferred tense in nearly every move in the AL abstracts.

The analyses so far has revealed some differences among the three journals. Although the different features of abstract moves among the three journals could partly be attributed to the different requirements of publishers as discussed earlier, the causes of the different verb tense usage in abstracts among the three journals remained obscure. Since Lau (2004) has detected some differences between the life science abstracts written by foreign scholars and those by Taiwanese PhD students (nonnative speakers), the factor of nativeness (i.e., native speaker vs. nonnative speaker) of the abstract authors was considered a possible cause resulting in the verb usage difference, and was thus further examined.

In the examination, whether an abstract author was a native speaker (NS) or a nonnative speaker (NNS) of English was roughly judged by the author's name, affiliation, and his/her portfolio on the Internet (note 9) (e.g., the author's photo, $\mathrm{CV}$ and educational background). If an abstract had multiple authors, the judgment was made on the first author. The distribution of the abstract authors' nativeness concerning their verb tense usage in each move is shown in Appendix E. The results revealed some interesting facts. To begin with, it has been found earlier that AL abstracts used the present tense in Move 4 (Results) more frequently than TQ and LL abstracts did. Further analysis of the nativeness of authors showed that native AL authors used the present tense more frequently than their nonnative counterparts. More specifically, among 17 native AL authors who included Move 4,13 of them $(76 \%)$ used the present tense; on the other hand, among 10 nonnative AL authors who included Move 4, only 5 (50\%) used the present tense. Thus, regarding Move 4 (Results), most native AL authors tended to use the present tense to show the continuing applicability of their findings, which then resulted in the high percentage of present tense in Move 4 in AL abstracts (see Appendix D).

Another interesting finding concerns nonnative authors' verb tense usage in Move 2 (Aim) in TQ and LL abstracts. The general tendency for verb tense in Move 2 was the present tense (see Table 7), but there was the same number of nonnative authors in TQ and LL abstracts who used either the present tense (TQ: 6; LL: 7) or the past tense (TQ: 6; LL: 7) in Move 2. This showed that some nonnative authors may use either the present tense or the past tense to describe the Aim of their research while most native authors may prefer the present tense only.

This further examination of authors' nativeness also provided another explanation for the high percentage of Move 1 (Background) in AL abstracts as found in the previous sections (see Table 3). It has been proposed that since the AL publisher has no specific requirements regarding the abstract length, AL authors can write whatever they want, say, giving a clear Background (Move 1) of their research. Yet, the analysis of authors' nativeness unexpectedly revealed that it was the native authors that included Move 1 far more frequently in their abstracts than the nonnative ones did, thus resulting in the high percentage of Move 1 in AL abstracts. In other words, given no length limit on abstracts, nonnative authors still tended to omit Move 1 and followed the four-move structure of abstracts, while native authors would usually think of Move 1 as an essential part and included it in their abstracts.

The above three findings demonstrate that there exist some minor differences between the abstracts written by native authors and those by nonnative authors. Since the examination here was a follow-up analysis and was also exploratory in nature, further systematic investigation, treating author's nativeness as a primary variable, is necessary if we want to uncover the major differences between the abstracts written by native authors and those by nonnative authors. Moreover, concerning the verb tense usage in abstracts, although the AL authors tended to use the present tense to report their Results (Move 4) than the other journal authors, the exact cause still remained unsolved. As verb tense usage is quite a complex issue in that authors may vary their choice of verb tense depending on the overall purpose, the context, the sequence of ideas, or even what is being expressed, an in-depth qualitative analysis of verb tense usage in each move, especially in Move 4 (Results), is worthwhile. The results of the present study serve as a good starting point for further examination of the verb tense usage in abstracts.

\section{Conclusion}

This study examined 90 research article abstracts from three journals in applied linguistics from two perspectives: 
the move structure features and the verb tense of each move. The major findings are summarized as follows.

First, with regard to move structures, the abstracts in the corpus tended to follow a four-move model (A-M-R-C) instead of a five-move one (B-A-M-R-C). Therefore, Move 1 (Background) is likely to be optional and the other four moves obligatory in applied linguistics abstracts. In addition, most of the abstracts usually opened with Move 2 (Aim) or Move 1 (Background), and closed with Move 5 (Conclusion) or Move 4 (Results). The abstracts in the corpus generally had 164 words, 6 sentences, and 4 move units; among the moves, Move 4 was the longest and Move 1 the shortest.

Second, concerning the verb tense of each move, the general pattern of the abstracts was to use the present tense in Move 1 (Background), Move 2 (Aim), and Move 5 (Conclusion), and to use the past tense in Move 3 (Method), and Move 4 (Results). Despite this tendency, there were some variations between the abstracts written by native authors and those by nonnative authors.

Third, there existed several differences in the abstract features among the three journals. To begin with, AL abstracts, compared with TQ and LL abstracts, had a higher percentage of Move 1 (Background), had a higher percentage of Move 1 as the opening move, and used more words to describe Move 1. In addition, in terms of verb tense usage, AL abstracts tended to use the present tense in Move 4 (Results) whereas TQ and LL abstracts often used the past tense. These differences between AL abstracts and TQ and LL abstracts might be due to the native authors in AL abstracts in that the native authors included Move 1 and used the present tense in Move 4 far more frequently than their nonnative AL counterparts. Regarding TQ abstracts, they differed from AL and LL abstracts in that they had a higher percentage of Move 5 (Conclusion), thus a higher percentage of Move 5 as the closing move. As for LL abstracts, they were in general significantly shorter in length than AL and TQ abstracts, thus containing fewer sentences and fewer move units than the other abstracts. This may be due to the length limit of an abstract (i.e., 100 to 120 words) required by the LL publisher.

This study, employing both qualitative and quantitative measures, has thus extended Santos's (1996) research and has advanced part of our knowledge of the applied linguistics abstracts. The present study not only offered a detailed description of the abstract features and of the move structure, but also showed a preferred verb tense in realizing each move. Since there is disciplinary variation in abstracts and there has been no full account in the writing handbooks or textbooks of how an abstract in applied linguistics should be written, this study may have some pedagogical implications for abstract writing. For one, novice writers or graduate students can be taught to construct a preferred four-move abstract or to vary the number of words in each move of an abstract based on the length limit. For another, beginning writers can take into consideration the preferred verb tense in each move of an abstract found in this study. Although it has been pointed out earlier that the choice of verb tense may depend on some contextual factors, the patterns found in the quantitative analysis are still useful references for beginning writers. In short, the results of this study may serve as concrete guidelines for novice writers to construct a proper research article abstract in applied linguistics.

Although the present study has highlighted several features of the abstracts in applied linguistics, it has its limitations. First, this study analyzed only abstracts of the empirical studies, and excluded those of the theoretical ones. Further examination can be conducted to reveal the patterns of theoretical abstracts, and compare those results with the patterns of empirical abstracts. Second, only the abstracts from three specific journals (i.e., TQ, AL, and LL) were examined in this study. Given the finding that there were differences among the abstracts in different journals (even within the same applied linguistics field), future research can focus on analyzing abstracts from the other journals expect the three used in this study. Third, the present study investigated only one element of linguistic realizations of moves, namely, verb tense. There are still many elements worth examining, such as voice, hedges, authorial stance, etc. Further studies can try exploring these features. Fourth, as the present study has shown that there existed some differences between the abstracts written by native authors and nonnative authors, the nativeness of abstract author is an interesting variable worth investigating in further research. In sum, it is hoped that, with more features of abstracts examined, there would be clearer guidelines for novice writers to construct an appropriate abstract in applied linguistics.

\section{References}

Anderson, K., \& Maclean, J. (1997). A genre analysis study of 80 medical abstracts. Edinburgh Working Papers in Applied Linguistics, 8, 1-23.

ANSI. (1979). The American standard for writing abstracts. New York: ANSI Publication.

American Psychological Association. (2001). Publication manual of the American psychological association. ( $5^{\text {th }}$ ed.). Washington DC: Author.

Bhatia, V. K. (1993). Analyzing genre: Language use in professional settings. London: Longman.

Brown, J. D. (1988). Understanding research in second language learning. Cambridge: Cambridge University Press.

Busch-Lauer, I. (1995). Abstracts in German medical journals: A linguistic analysis. Information Processing \& 
Management, 31(5). 769-776. doi:10.1016/0306-4573(95)00024-B, http://dx.doi.org/10.1016/0306-4573(95)00024-B

Cross, C., \& Oppenheim, C. (2006). A genre analysis of scientific abstracts. Journal of Documentation, 62(4), 428-446. doi:10.1108/00220410610700953, http://dx.doi.org/10.1108/00220410610700953

Egbert, J. (2007). Quality analysis of journals in TESOL and applied linguistics. TESOL Quarterly, 41(1), 157-171.

Hartley, J., \& Benjamin, M. (1998). An evaluation of structured abstracts in journals published by the British psychological society. British Journal of Educational Psychology, 68, 443-456. doi:10.1111/j.2044-8279.1998.tb01303.x, http://dx.doi.org/10.1111/j.2044-8279.1998.tb01303.x

Hartley, J., \& Sydes, M. (1997). Are structured abstracts easier to read than traditional ones? Journal of Research in Reading, 20(2), 122-136. doi:10.1111/1467-9817.00025, http://dx.doi.org/10.1111/1467-9817.00025

Hartley, J., Sydes, M., \& Blurton, A. (1996). Obtaining information accurately and quickly: Are structured abstracts more efficient? Journal of Information Science, 22(5), 349-356. doi:10.1177/016555159602200503, http://dx.doi.org/10.1177/016555159602200503

Holmes, R. (1997). Genre analysis, and the social sciences: An investigation of the structure of research article discussion sections in three disciplines. English for Specific Purposes, 16(4), 321-337. doi:10.1016/S0889-4906(96)00038-5, http://dx.doi.org/10.1016/S0889-4906(96)00038-5

Hyland, K. (2000). Disciplinary discourse: Social interactions in academic writing. London: Longman.

Lau, H. H. (2004). The structure of academic journal abstracts written by Taiwanese PhD students. Taiwan Journal of TESOL, 1(1), 1-25.

Lorés, R. (2004). On RA abstracts: From rhetorical structure to thematic organization. English for Specific Purposes, 23(3), 280-302. doi:10.1016/j.esp.2003.06.001, http://dx.doi.org/10.1016/j.esp.2003.06.001

Martín, P. M. (2003). A genre analysis of English and Spanish research paper abstracts in experimental social sciences. English for Specific Purposes, 22(1), 25-43. doi:10.1016/S0889-4906(01)00033-3, http://dx.doi.org/10.1016/S0889-4906(01)00033-3

Pho, P. Z. (2008). Research article abstracts in applied linguistics and educational technology: A study of linguistic realizations of rhetorical structure and authorial stance. Discourse Studies, 10(2), 231-250. doi:10.1177/1461445607087010, http://dx.doi.org/10.1177/1461445607087010

Salager-Meyer, F. (1992). A text-type and move analysis study of verb tense and modality distribution in medical English abstracts. English for Specific Purposes, 11(2), 93-113. doi:10.1016/S0889-4906(05)80002-X, http://dx.doi.org/10.1016/S0889-4906(05)80002-X

Santos, M. B. (1996). The textual organization of research paper abstracts in applied linguistics. Text, 16(4), 481-499. doi:10.1515/text.1.1996.16.4.481, http://dx.doi.org/10.1515/text.1.1996.16.4.481

Swales, J. M. (1990). Genre analysis: English in academic and research settings. Cambridge: Cambridge University Press.

Swales, J. M., \& Feak, C. B. (2004). Academic writing for graduate students. (2 ${ }^{\text {nd }}$ ed.). Ann Arbor: University of Michigan Press.

Ventola, E. (1994). Abstracts as an object of linguistic study. In S. Čmejrková, F. Daneš, \& E. Havlová (Eds.). Writing vs. speaking: Language, text, discourse, communication (pp.333-352). Tübingen: Gunter Narr.

Weissberg, R., \& Buker, S. (1990). Writing up research: Experimental research report writing for students of English. New Jersey: Prentice Hall.

\section{Notes}

Note 1. Structured abstracts, unlike traditional ones, contain sub-headings, such as background, aims, methods, results and conclusions. They appear in most current medical journals and four journals published by the British Psychological Society-the British Journal of Clinical Psychology, the British Journal of Educational Psychology, the British Journal of Health Psychology, and the Legal and Criminological Psychology.

Note 2. Another line of research in abstracts is the investigation of the effectiveness of structured abstracts as done in a series of studies by Hartley and his colleagues (e.g., Hartley, Sydes \& Blurton, 1996; Hartley \& Sydes, 1997; Hartley \& Benjamin, 1998). As the structured abstracts seldom appear in applied linguistics, the author did not venture into this line of research, but focused on the features of the traditional abstracts.

Note 3. The top seven journals were Applied Linguistics, English Language Teaching Journal, Journal of Second Language Writing, Language Learning, Modern Language Journal, Studies in Second Language Acquisition, and TESOL Quarterly.

Note 4. TESOL Quarterly belongs to Teachers of English Speakers of Other Languages, Inc., which requires an 
informative abstract of not more than 200 words along with the manuscript. Applied Linguistics belongs to the Oxford University Press, which does not make specifications for abstracts. Language Learning belongs to Blackwell Publishing, which requires an abstract of 100 to 120 words accompanying the manuscript.

Note 5. Sources of the examples are listed in Appendix A. Due to space limit of this article, the complete sources of the 90 articles in the corpus were not provided here, but they are available from the researcher upon request via E-mail.

Note 6. The distribution of the five moves in Santos (1996) was as follows: $43 \%$ of the abstracts had Move 1, 99\% had Move 2, 98\% had Move 3, 80\% had Move 4, and 53\% had Move 5.

Note 7. Examples of the move structures found in the corpus are as follows: M-R [LL 6]; A-R-C [TQ 23]; B-A-M-R [AL 14]; B-A-M-R-C [AL 1]; A-M-R-A-R-C [TQ 5].

Note 8. Abstracts containing five moves and four moves were all calculated respectively in Table 4 despite the fact that some abstracts had recurring moves (e.g., A-M-A-R-C) or had a sequence different from the standard (B)-A-M-R-C (e.g., M-A-R-C).

Note 9. The researcher acknowledged that it is not easy to define a native speaker, but with these criteria, approximation of the authors' nativeness can be reached.

Appendix A. Selected corpus articles exemplified in the study

TESOL Quarterly:

TQ 2 Goto Butler, Y. (2007). How are nonnative-English-speaking teachers perceived by young learners? TESOL Quarterly, 41(4), 731-755.

TQ 3 Lamb, M. (2007). The impact of school on EFL learning motivation: An Indonesian case study. TESOL Quarterly, 41(4), 757-780.

TQ 5 Taguchi, N. (2007). Development of speed and accuracy in pragmatic comprehension in English as a foreign language. TESOL Quarterly, 41(2), 313-338.

TQ 23 Leibowitz, B. (2005). Learning in an additional language in a multilingual society: A South African case study on university-level writing. TESOL Quarterly, 39(4), 661-681.

Applied Linguistics:

AL 1 Pomerantz, A., \& Bell, N. D. (2007). Learning to play, playing to learn: FL learners as multicompetent language users. Applied Linguistics, 28(4), 556-578.

AL 14 Mackey, A. (2006). Feedback, noticing and instructed second language learning. Applied Linguistics, 27(3), 405-430.

AL 16 Ellis, R. (2006). Modeling learning difficulty and second language proficiency: The differential Language Learning: contributions of implicit and explicit knowledge. Applied Linguistics, 27(3), 431-463.

LL 2 Geyer, N. (2007). Self-qualification in L2 Japanese: An interface of pragmatic, grammatical, and discourse competences. Language Learning, 57(3), 337-367.

LL 6 Schiff, R., \& Calif, S. (2007). Role of phonological and morphological awareness in L2 oral word reading. Language Learning, 57(2), 271-298.

LL 19 Nikolov, M. (2006). Test-taking strategies of 12- and 13-year-old Hungarian learners of EFL: Why whales have migraines. Language Learning, 56(1), 1-51.

LL 21 Csizér, K., \& Dörnyei, Z. (2005). Language learners' motivational profiles and their motivated learning behavior. Language Learning, 55(4), 613-659.

Appendix B. Descriptive statistics of the abstract features in three journals

\begin{tabular}{llrrrr}
\hline & & Mean & S.D. & Min & Max \\
\hline Length $^{\text {a }}$ & TQ & 171.97 & 28.22 & 117 & 223 \\
& AL & 184.20 & 36.19 & 107 & 292 \\
& LL & 134.87 & 31.68 & 98 & 237 \\
\hline Sentences & TQ & 6.83 & 1.53 & 4 & 10 \\
& AL & 6.40 & 1.89 & 3 & 11 \\
& LL & 5.43 & 1.43 & 2 & 9 \\
\hline Units & TQ & 4.73 & 1.05 & 3 & 7 \\
& AL & 4.67 & 1.12 & 3 & 8 \\
& LL & 4.00 & .98 & 2 & 7 \\
\hline
\end{tabular}




\begin{tabular}{lllllr}
\hline $\mathrm{B}^{\mathrm{a}}$ & TQ & 16.57 & 29.04 & 0 & 103 \\
& AL & 34.80 & 35.98 & 0 & 117 \\
& LL & 8.93 & 16.40 & 0 & 48 \\
\hline $\mathrm{A}^{\mathrm{a}}$ & TQ & 37.10 & 22.97 & 4 & 110 \\
& AL & 34.87 & 22.90 & 0 & 84 \\
& LL & 29.60 & 19.84 & 0 & 75 \\
\hline $\mathrm{M}^{\mathrm{a}}$ & TQ & 35.23 & 20.55 & 0 & 79 \\
& AL & 42.30 & 37.85 & 0 & 159 \\
& LL & 36.63 & 25.55 & 6 & 105 \\
\hline $\mathrm{R}^{\mathrm{a}}$ & TQ & 50.30 & 27.88 & 0 & 106 \\
& AL & 42.77 & 26.50 & 0 & 113 \\
& LL & 44.20 & 27.28 & 0 & 108 \\
\hline $\mathrm{C}^{\mathrm{a}}$ & TQ & 32.77 & 18.70 & 0 & 78 \\
& AL & 29.43 & 30.26 & 0 & 127 \\
& LL & 15.50 & 15.66 & 0 & 46 \\
\hline
\end{tabular}

\footnotetext{
${ }^{\mathrm{a}}$ The unit for these categories is number of words.
}

Appendix C. ANOVA and multiple comparisons of the abstract features in three journals ANOVA

\begin{tabular}{llrrrrc}
\hline Source & & Sum of Square & df & Mean Square & F & Sig. \\
\hline \multirow{2}{*}{ Length } & Between groups & 39598.42 & 2 & 19799.21 & 19.10 & $.000^{*}$ \\
& Within groups & 90193.23 & 87 & 1036.70 & & \\
\hline \multirow{2}{*}{ Sentences } & Between groups & 30.82 & 2 & 15.41 & 5.81 & $.004^{*}$ \\
& Within groups & 230.73 & 87 & 2.65 & & \\
\hline \multirow{2}{*}{ Units } & Between groups & 9.87 & 2 & 4.93 & 4.45 & $.015^{*}$ \\
& Within groups & 96.53 & 87 & 1.11 & & \\
\hline $\mathrm{B}$ & Between groups & 10598.07 & 2 & 5299.03 & 6.61 & $.002^{*}$ \\
& Within groups & 69788.03 & 87 & 802.16 & & \\
\hline $\mathrm{A}$ & Between groups & 889.76 & 2 & 444.88 & .92 & .401 \\
& Within groups & 41929.37 & 87 & 481.95 & & \\
\hline $\mathrm{M}$ & Between groups & 840.09 & 2 & 420.04 & .50 & .607 \\
& Within groups & 72728.63 & 87 & 835.96 & & \\
\hline $\mathrm{R}$ & Between groups & 960.16 & 2 & 480.08 & .65 & .526 \\
& Within groups & 64492.47 & 87 & 741.29 & & \\
\hline $\mathrm{C}$ & Between groups & 5033.87 & 2 & 2516.93 & 4.10 & $.009^{*}$ \\
& Within groups & 43802.23 & 87 & 503.47 & & \\
\hline
\end{tabular}

$\mathrm{p}<.05$

Multiple comparisons

\begin{tabular}{lllcrll}
\hline & & & Mean Difference & Std. Error & Sig. \\
& $(\mathrm{I})$ & $(\mathrm{J})$ & -12.23 & 8.31 & .343 \\
\hline Length & TQ & AL & 37.10 & 8.31 & $.000^{*}$ \\
& TQ & LL & 49.33 & 8.31 & $.000^{*}$ \\
\hline Sentences & AL & LL & .43 & .42 & .590 \\
& TQ & AL & 1.40 & .42 & $.005^{*}$ \\
& TQ & LL & .97 & .42 & .077 \\
\hline Units & AL & LL & .07 & .27 & .970 \\
\hline
\end{tabular}




\begin{tabular}{lllrll}
\hline & TQ & LL & .73 & .27 & $.030^{*}$ \\
& AL & LL & .67 & .27 & .055 \\
\hline B & TQ & AL & -18.23 & 7.31 & $.050^{*}$ \\
& TQ & LL & 7.63 & 7.31 & .582 \\
& AL & LL & 25.87 & 7.31 & $.003^{*}$ \\
\hline C & TQ & AL & 3.33 & 5.79 & .848 \\
& TQ & LL & 17.27 & 5.79 & $.015^{*}$ \\
& AL & LL & 13.93 & 5.79 & .061 \\
\hline
\end{tabular}

$\mathrm{p}<.05$

Appendix D. Verb tense frequency in each move in three journals

\begin{tabular}{|c|c|c|c|c|c|c|}
\hline & \multicolumn{2}{|c|}{ TQ } & \multicolumn{2}{|c|}{$\mathrm{AL}$} & \multicolumn{2}{|c|}{ LL } \\
\hline & & & & & & \\
\hline Present & 10 & $100 \%$ & 14 & $88 \%$ & 8 & $100 \%$ \\
\hline Past & 0 & $0 \%$ & 1 & $6 \%$ & 0 & $0 \%$ \\
\hline Present + past & 0 & $0 \%$ & 1 & $6 \%$ & 0 & $0 \%$ \\
\hline \multicolumn{7}{|l|}{ (A) } \\
\hline Present & 17 & $59 \%$ & 26 & $96 \%$ & 13 & $48 \%$ \\
\hline Past & 9 & $31 \%$ & 1 & $4 \%$ & 11 & $41 \%$ \\
\hline Present + past & 3 & $10 \%$ & 0 & $0 \%$ & 3 & $11 \%$ \\
\hline \multicolumn{7}{|l|}{ (M) } \\
\hline Present & 4 & $17 \%$ & 8 & $42 \%$ & 2 & $8 \%$ \\
\hline Past & 18 & $75 \%$ & 11 & $58 \%$ & 21 & $88 \%$ \\
\hline Present + past & 2 & $8 \%$ & 0 & $0 \%$ & 1 & $4 \%$ \\
\hline \multicolumn{7}{|l|}{ (R) } \\
\hline Present & 5 & $19 \%$ & 18 & $67 \%$ & 5 & $18 \%$ \\
\hline Past & 22 & $82 \%$ & 8 & $30 \%$ & 22 & $79 \%$ \\
\hline Present + past & 0 & $0 \%$ & 1 & $4 \%$ & 1 & $4 \%$ \\
\hline \multicolumn{7}{|l|}{ (C) } \\
\hline Present & 26 & $93 \%$ & 18 & $86 \%$ & 13 & $77 \%$ \\
\hline Past & 1 & $4 \%$ & 2 & $10 \%$ & 1 & $6 \%$ \\
\hline Present + past & 1 & $4 \%$ & 1 & $5 \%$ & 3 & $18 \%$ \\
\hline
\end{tabular}

\begin{tabular}{|c|c|c|c|c|c|c|c|c|}
\hline \multirow[b]{3}{*}{$\mathrm{N}=30$} & \multicolumn{2}{|c|}{ TQ } & \multicolumn{2}{|c|}{$\mathrm{AL}$} & \multicolumn{2}{|c|}{ LL } & \multicolumn{2}{|c|}{ Totality } \\
\hline & NS & NNS & NS & NNS & NS & NNS & NS & NNS \\
\hline & $\begin{array}{l}17 \\
(57 \%)\end{array}$ & $\begin{array}{l}13 \\
(43 \%)\end{array}$ & $\begin{array}{l}19 \\
(63 \%)\end{array}$ & $\begin{array}{l}11 \\
(37 \%)\end{array}$ & $\begin{array}{l}13 \\
(43 \%)\end{array}$ & $\begin{array}{l}17 \\
(57 \%)\end{array}$ & $\begin{array}{l}49 \\
(54 \%)\end{array}$ & $\begin{array}{l}41 \\
(46 \%)\end{array}$ \\
\hline \multicolumn{9}{|l|}{ (B) } \\
\hline Present & 5 & 5 & 12 & 2 & 5 & 3 & 22 & 10 \\
\hline Past & 0 & 0 & 1 & 0 & 0 & 0 & 1 & 0 \\
\hline Pre+past & 0 & 0 & 0 & 1 & 0 & 0 & 0 & 1 \\
\hline \multicolumn{9}{|l|}{ (A) } \\
\hline Present & 11 & 6 & 17 & 9 & 6 & 7 & 34 & 22 \\
\hline Past & 3 & 6 & 0 & 1 & 4 & 7 & 7 & 14 \\
\hline Pre+past & 2 & 1 & 0 & 0 & 0 & 3 & 2 & 4 \\
\hline \multicolumn{9}{|l|}{ (M) } \\
\hline Present & 3 & 1 & 5 & 3 & 0 & 2 & 8 & 6 \\
\hline Past & 8 & 10 & 7 & 4 & 11 & 10 & 26 & 24 \\
\hline
\end{tabular}




\begin{tabular}{|c|c|c|c|c|c|c|c|c|}
\hline Pre+past & 1 & 1 & 0 & 0 & 0 & 1 & 1 & 2 \\
\hline \multicolumn{9}{|l|}{ (R) } \\
\hline Present & 5 & 0 & 13 & 5 & 1 & 4 & 19 & 9 \\
\hline Past & 11 & 11 & 4 & 4 & 12 & 10 & 27 & 25 \\
\hline Pre+past & 0 & 0 & 0 & 1 & 0 & 1 & 0 & 2 \\
\hline \multicolumn{9}{|l|}{ (C) } \\
\hline Present & 17 & 9 & 10 & 8 & 5 & 8 & 32 & 25 \\
\hline Past & 0 & 1 & 0 & 2 & 1 & 0 & 1 & 3 \\
\hline Pre+past & 0 & 1 & 1 & 0 & 0 & 3 & 1 & 4 \\
\hline \multicolumn{9}{|c|}{ Table 1. Framework for Move Analysis } \\
\hline \multicolumn{4}{|c|}{ Moves (Swales and Feak 2004) } & \multicolumn{5}{|c|}{ Functions (Santos 1996) } \\
\hline \multicolumn{4}{|c|}{ Move 1: Background (B) } & \multicolumn{5}{|c|}{ Situating the research } \\
\hline \multicolumn{4}{|c|}{ Move 2: Aim (A) } & \multicolumn{5}{|c|}{ Presenting the research } \\
\hline \multicolumn{4}{|c|}{ Move 3: Method (M) } & \multicolumn{5}{|c|}{ Describing the methodology } \\
\hline \multicolumn{4}{|c|}{ Move 4: Results (R) } & \multicolumn{5}{|c|}{ Summarizing the results } \\
\hline \multicolumn{4}{|c|}{ Move 5: Conclusion (C) } & \multicolumn{5}{|c|}{ Discussing the research } \\
\hline
\end{tabular}

Table 2. Analysis of the Move Structure of an Abstract

\begin{tabular}{|c|c|c|c|c|c|c|c|c|c|c|}
\hline Sentence & \multicolumn{8}{|c|}{ Text (LL 2) } & Move & $\begin{array}{l}\text { No. of } \\
\text { words }\end{array}$ \\
\hline 1 & \multicolumn{8}{|c|}{$\begin{array}{l}\text { In Japanese, self-qualification, or a qualifying segment of talk that reduces } \\
\text { the force of the speaker's own utterances, is frequently introduced with } \\
\text { contrastive markers, such as demo, kedo, and ga. }\end{array}$} & $\mathrm{B}$ & 30 \\
\hline 2 & \multicolumn{8}{|c|}{$\begin{array}{l}\text { This study explores the relationship between the grammatical and } \\
\text { pragmatic competence of Japanese L2 learners }\end{array}$} & A & 15 \\
\hline & \multicolumn{8}{|c|}{$\begin{array}{l}\text { by examining their use of such self-qualification in a corpus of oral } \\
\text { proficiency interviews. }\end{array}$} & M & 14 \\
\hline 3 & \multicolumn{8}{|c|}{$\begin{array}{l}\text { It demonstrates that successful self-qualification is achieved not only by } \\
\text { the placement of appropriate connective expressions but also through } \\
\text { effective use of foregrounding and/or backgrounding discourse } \\
\text { mechanisms. }\end{array}$} & $\mathrm{R}$ & 27 \\
\hline 4 & \multicolumn{8}{|c|}{$\begin{array}{l}\text { The results indicate a close relationship between pragmatic, grammatical, } \\
\text { and discourse competence in learner language. }\end{array}$} & $\mathrm{C}$ & 15 \\
\hline Features: & \multicolumn{10}{|c|}{ B-A-M-R-C (4 sentences, 101 words in length) } \\
\hline$(\mathrm{N}=90)$ & \multicolumn{2}{|c|}{ B } & t & & \multicolumn{2}{|c|}{$\mathrm{M}$} & \multicolumn{2}{|c|}{$\mathrm{R}$} & \multicolumn{2}{|c|}{$\mathrm{C}$} \\
\hline TQ & 10 & $33 \%$ & 30 & $100 \%$ & 29 & $97 \%$ & 27 & $90 \%$ & 28 & $93 \%$ \\
\hline $\mathrm{AL}$ & 19 & $63 \%$ & 28 & $93 \%$ & 28 & $93 \%$ & 27 & $90 \%$ & 21 & $70 \%$ \\
\hline LL & 8 & $27 \%$ & 28 & $93 \%$ & 30 & $100 \%$ & 28 & $93 \%$ & 18 & $60 \%$ \\
\hline (Total) & 37 & $41 \%$ & 86 & $96 \%$ & 87 & $97 \%$ & 82 & $91 \%$ & 67 & $74 \%$ \\
\hline
\end{tabular}


Table 4. Distribution of Abstracts with Five Moves and Four Moves

\begin{tabular}{cccccc}
\hline & \multicolumn{2}{c}{ Five moves } & \multicolumn{2}{c}{ Four moves } \\
TQ & \multicolumn{2}{c}{$\mathrm{B}, \mathrm{A}, \mathrm{M}, \mathrm{R}, \mathrm{C})$} & \multicolumn{2}{c}{$(\mathrm{A}, \mathrm{M}, \mathrm{R}, \mathrm{C})$} \\
$\mathrm{AL}$ & 6 & $20 \%$ & 18 & $60 \%$ \\
LL & 10 & $33 \%$ & 6 & $20 \%$ \\
(Total) & 4 & $13 \%$ & 11 & $37 \%$ \\
\hline
\end{tabular}

Table 5. Distribution of Opening and Closing Moves

\begin{tabular}{|c|c|c|c|c|c|c|c|c|c|c|}
\hline (Opening) & \multicolumn{2}{|c|}{ B } & \multicolumn{2}{|c|}{$\mathrm{A}$} & \multicolumn{2}{|c|}{$\mathrm{M}$} & \multicolumn{2}{|c|}{$\mathrm{R}$} & \multicolumn{2}{|c|}{$\mathrm{C}$} \\
\hline TQ & 9 & $30 \%$ & 20 & $67 \%$ & 1 & $3 \%$ & \multicolumn{2}{|c|}{0} & \multicolumn{2}{|c|}{0} \\
\hline $\mathrm{AL}$ & 15 & $50 \%$ & 11 & $37 \%$ & 4 & $13 \%$ & \multicolumn{2}{|c|}{0} & \multicolumn{2}{|c|}{0} \\
\hline LL & 7 & $23 \%$ & 21 & $70 \%$ & 2 & $7 \%$ & \multicolumn{2}{|c|}{0} & \multicolumn{2}{|c|}{0} \\
\hline (Total) & 31 & $34 \%$ & 52 & $58 \%$ & 7 & $8 \%$ & \multicolumn{2}{|c|}{$\mathbf{0}$} & \multicolumn{2}{|c|}{$\mathbf{0}$} \\
\hline \multicolumn{11}{|l|}{ (Closing) } \\
\hline TQ & \multicolumn{2}{|c|}{0} & \multicolumn{2}{|c|}{0} & \multicolumn{2}{|c|}{0} & 2 & $7 \%$ & 28 & $93 \%$ \\
\hline $\mathrm{AL}$ & \multicolumn{2}{|c|}{0} & 1 & $3 \%$ & 1 & $3 \%$ & 7 & $23 \%$ & 21 & $70 \%$ \\
\hline LL & \multicolumn{2}{|c|}{0} & 1 & $3 \%$ & \multicolumn{2}{|c|}{0} & 11 & $37 \%$ & 18 & $60 \%$ \\
\hline (Total) & \multicolumn{2}{|c|}{ 0 } & 2 & $2 \%$ & 1 & $1 \%$ & 20 & $22 \%$ & 67 & $74 \%$ \\
\hline
\end{tabular}

Table 6. Descriptive Statistics of Abstract Features

\begin{tabular}{lrrrr}
\hline$(\mathrm{N}=90)$ & Mean & S.D. & Min & Max \\
\hline Abstract length $^{\mathrm{a}}$ & 163.68 & 38.19 & 98 & 292 \\
No. of sentences & 6.22 & 1.71 & 2 & 11 \\
No. of move units & 4.47 & 1.09 & 2 & 8 \\
$\mathrm{~B}^{\mathrm{a}}$ & 20.10 & 30.05 & 0 & 117 \\
$\mathrm{~A}^{\mathrm{a}}$ & 33.86 & 21.93 & 0 & 110 \\
$\mathrm{M}^{\mathrm{a}}$ & 38.06 & 28.75 & 0 & 159 \\
$\mathrm{R}^{\mathrm{a}}$ & 45.76 & 27.12 & 0 & 113 \\
$\mathrm{C}^{\mathrm{a}}$ & 25.90 & 23.43 & 0 & 127 \\
\hline
\end{tabular}

${ }^{\mathrm{a}}$ The unit for these categories is number of words.

Table 7. Verb Tense Frequency in Each Move

\begin{tabular}{lrrrrrrrrrr}
\hline & \multicolumn{2}{c}{$\mathrm{B}$} & \multicolumn{2}{c}{$\mathrm{A}$} & \multicolumn{2}{c}{$\mathrm{M}$} & \multicolumn{2}{c}{$\mathrm{R}$} & \multicolumn{3}{c}{$\mathrm{C}$} \\
\hline Present & $\mathbf{3 2}$ & $\mathbf{9 4 \%}$ & $\mathbf{5 6}$ & $\mathbf{6 8 \%}$ & 14 & $21 \%$ & 29 & $35 \%$ & $\mathbf{5 7}$ & $\mathbf{8 6 \%}$ \\
Past & 1 & $3 \%$ & 21 & $25 \%$ & $\mathbf{5 1}$ & $\mathbf{7 6 \%}$ & $\mathbf{5 1}$ & $\mathbf{6 2 \%}$ & 4 & $6 \%$ \\
Present+past & 1 & $3 \%$ & 6 & $7 \%$ & 2 & $3 \%$ & 2 & $2 \%$ & 5 & $8 \%$ \\
\multicolumn{1}{r}{ (Total) } & 34 & & 83 & & 67 & & 82 & & 66 & \\
\hline
\end{tabular}

